\title{
Attraction to amino acids by Lymnaea acuminata, the snail host of Fasciola species
}

F. Tiwari and D.K. Singh
Department of Zoology, Deen Dayal Upadhyay Gorakhpur University, Gorakhpur, UP, India

\section{Correspondence \\ D.K. Singh \\ Malacology Laboratory \\ Department of Zoology \\ DDU Gorakhpur University \\ Gorakhpur 273009, UP \\ India \\ E-mail: dksingh_gpu@yahoo.co.in}

Received October 23, 2002 Accepted January 21, 2004

\section{Abstract}

Adult Lymnaea acuminata (average length 20-22 mm) were collected locally from lakes and low-lying submerged fields from Gorakhpur. The chemoattraction studies were made in round glass aquaria measuring $30 \mathrm{~cm}$ in diameter and filled to a depth of $10 \mathrm{~mm}$ with $500 \mathrm{ml}$ dechlorinated tap water. Each aquarium was divided into four concentric zones. At the starting time of the assay 10 snails were placed on the circumference of outermost zone 0 . Snail attractant pellets (SAP) were added simultaneously in the center of central zone 3. SAP of different amino acids were prepared at concentrations of 10, 20, 50, 80 and 100 $\mathrm{mM} / 2 \%$ agar solution and, subsequently, spread to a uniform thickness of $5 \mathrm{~mm}$. After cooling, SAP were cut in small pieces of $5 \mathrm{~mm}$ in diameter. Lymnaea acuminata's attraction to amino acids was studied using different amino acid concentrations in SAP. Pellets containing amino acids with non-polar $\mathrm{R}$ groups (proline and tryptophan), a charged polar group (arginine) and uncharged polar R groups (serine, citrulline and asparagine) were tested. The snails were more attracted to the uncharged polar $\mathrm{R}$ group amino acid serine than to other groups of amino acids. The preferred amino acid concentration was $80 \mathrm{mM}$. The attraction of snails to different amino acids was concentration dependent. Snails could discriminate amongst the different amino acids at $\geq 50 \mathrm{mM}$.

Fascioliasis is an important live-stock health problem $(1,2)$. This disease is transmitted by the flukes Fasciola hepatica and F. gigantica through the vector snail Lymnaea acuminata (1). Snail control with molluscicides has been one of the effective methods used for rapid and effective control of this disease. Bait formulation of different molluscicides would be an effective tool for selective killing of the snail with minimal adverse effect on the environment. It is therefore important to identify strong attractant compounds for preparing bait formulations containing the desired attractant and molluscicides. Snails, like other gastropod molluscs, use chemical clues to locate food sources (3-6).

In the present study, a variety of amino acid bioassay methods was screened to determine the behavioral responses of the snail L. acuminata. Amino acids were identified in the snail modular system as chemicals diffusing from aquatic organisms and are probably used by the snails as indicators to identify their food (7).

Adult L. acuminata snails (mean length: 
$2.25 \pm 0.20 \mathrm{~cm}$ ) were collected locally from lakes and low-lying submerged fields and were used as test animals. The snails were acclimated to laboratory conditions for $72 \mathrm{~h}$.

Snail attractant pellets (SAP) of agar containing different amino acids such as arginine, proline, tryptophan, serine, citrulline, and asparagine were prepared according to the method of Madsen (8). Three groups of amino acids, i.e., i) non-polar $\mathrm{R}$ group (proline and tryptophan), ii) charged polar $\mathrm{R}$ group (arginine), and iii) uncharged polar $\mathrm{R}$ group (serine, asparagine and citrulline) were used. Each amino acid was prepared at concentrations of $10,20,50,80$ and $100 \mathrm{mM} /$ $2 \%$ agar solution. The preparations were spread to a uniform thickness of $5 \mathrm{~mm}$ and, after cooling, SAP were cut out using a corer measuring $5 \mathrm{~mm}$ in diameter.

The chemoattraction studies were carried out in round glass aquaria measuring 30 $\mathrm{cm}$ in diameter. Each aquarium was divided into 4 concentric zones. Zone 3 (central zone) zones 2 and 1 (middle zones) and zone 0 (outer zone) had diameters of 13, 18, 24 and $30 \mathrm{~cm}$ each, respectively. Zone 0 had an area of $254 \mathrm{~cm}^{2}$ around the inside edge of the aquarium. A small annular elevation was made in the center of the aquarium (zone 3 ). Each container was filled to a depth of 10 $\mathrm{mm}$ with $500 \mathrm{ml}$ dechlorinated water. The containers were maintained at $25 \pm 1^{\circ} \mathrm{C}$. Ten snails of the same size were first placed in zone 0 at equally spaced positions and SAP were simultaneously added to zone 3 . The position of each snail was recorded at 15min intervals for $2 \mathrm{~h}$. A clear glass aquarium containing agar alone was used as control for each experiment. Each set of experiments was repeated six times. The behavioral responses of snails to SAP containing different amino acids were observed and two-way ANOVA was applied to determine significant alterations in behavior (9).

Figure 1 shows the number of snails attracted towards the SAP containing different concentrations of amino acids in zone 3 . The uncharged polar $\mathrm{R}$ group amino acid serine caused highest attraction of snails at $80 \mathrm{mM}$. After $2 \mathrm{~h}$ of the experiment, the behavioral responses of snails showed high attraction to the SAP containing $80 \mathrm{mM}$ arginine, proline, tryptophan, serine, and asparagine. The citrulline-containing SAP showed the highest attraction at $100 \mathrm{mM}$ (Figure 1). There was a significant $(\mathrm{P}<0.05)$ concentration-
Figure 1. Number of snails that reached the zone where the pellets containing amino acids were located. Data are reported as mean number of snails of six replicates that reached zone 3 which contained the pellets $2 \mathrm{~h}$ after the beginning of the experiment.

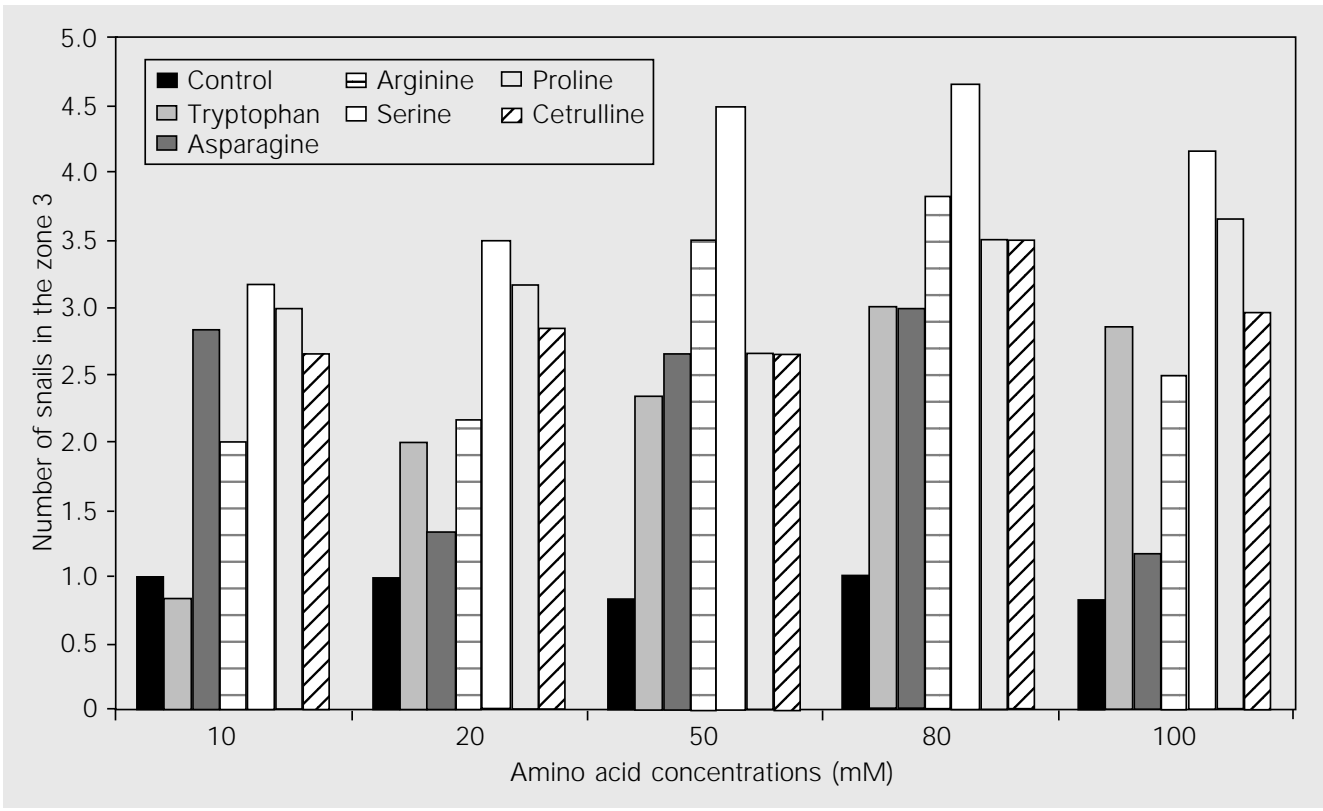


dependent variation in mean number of snails in the third zone around SAP of different amino acids $2 \mathrm{~h}$ after the beginning of the experiment. Accumulation of snails on the serine-containing SAP was highest at all concentrations (Figure 1). There was no significant variation in the number of snails present in different zones containing SAP with different amino acid concentrations. A significant variation in the number of snails on SAP containing different amino acids was observed only for $50 \mathrm{mM}$ concentrations after $1 \mathrm{~h}$ (Table 1).

Except for citrulline, all amino acids attracted snails most when present in SAP at $80 \mathrm{mM}$. Among all the amino acids of the uncharged polar group, serine was the most preferred by the snails at all concentrations. Abd El-Hamid (7) reported that proline is the preferred attractant for Biomphalaria alexandrina and suggested that this high attraction of proline may be due to the fact that it is released from the snails into the surrounding water as a signal (10). However, in the present study serine was found to be the most preferred amino acid. It is possible that differences in behavioral responses between $L$. acuminata and other snails may be due to the differences in the feeding behavior and metabolism of these species. The higher attraction to serine by snails may be due to its more rapid diffusion in different zones since its molecular weight is lower than that of other amino acids. The attraction of all amino acids, except asparagine, in SAP was dose dependent $(\mathrm{P}<0.05)$. Usually, $L$. acuminata snails are less responsive to amino acids (63.2\% maximum) than $B$. alexandrina ( $85.7 \%$ maximum) when exposed to the SAP containing different concentrations of amino acids (7). There was no significant difference in number of snails in the different zones in the presence of different concentrations of the various amino acids, indicating that within 1 and $2 \mathrm{~h}$ these amino acids diffused throughout all three zones. There was no significant variation in number
Table 1. Distribution of Lymnaea acuminata snails in the various zones around snail attractant pellets (SAP) containing $50 \mathrm{mM}$ amino acids 1 and $2 \mathrm{~h}$ after the beginning of the experiment.

\begin{tabular}{llccc}
\hline \multirow{2}{*}{ Attractant } & Time (h) & \multicolumn{4}{c}{ Mean number of entries of snails around attractant } \\
\cline { 3 - 5 } & & $Z_{1}$ & $Z_{2}$ & $Z_{3}$ \\
\hline Agar (control) & 1 & $0.66 \pm 0.21(33.1)$ & $0.66 \pm 0.33(33.1)$ & $0.50 \pm 0.22(25.1)$ \\
& 2 & $1.66 \pm 0.42(41.6)$ & $1.50 \pm 0.42(37.5)$ & $0.83 \pm 0.30(20.8)$ \\
Arginine & $1^{*}$ & $1.33 \pm 0.42(27.5)$ & $1.16 \pm 0.30(24.0)$ & $2.33 \pm 0.49(48.3)$ \\
& 2 & $2.00 \pm 0.25(32.4)$ & $1.83 \pm 0.30(29.7)$ & $2.33 \pm 0.95(37.8)$ \\
Proline & $1^{*}$ & $1.16 \pm 0.30(33.2)$ & $1.00 \pm 0.25(28.6)$ & $1.33 \pm 0.33(38.1)$ \\
& 2 & $3.00 \pm 0.44(41.8)$ & $1.50 \pm 0.22(20.9)$ & $2.66 \pm 0.42(37.1)$ \\
Tryptophan & $1^{*}$ & $0.50 \pm 0.22(13.6)$ & $1.33 \pm 0.33(36.3)$ & $1.83 \pm 0.54(50.0)$ \\
& 2 & $1.33 \pm 0.21(18.5)$ & $2.33 \pm 0.71(32.5)$ & $3.50 \pm 0.96(48.8)$ \\
Serine & $1^{*}$ & $1.00 \pm 0.25(20.0)$ & $1.50 \pm 0.22(30.0)$ & $2.50 \pm 0.34(50.0)$ \\
& 2 & $2.33 \pm 0.61(27.4)$ & $1.66 \pm 0.33(19.5)$ & $4.50 \pm 0.56(53.0)$ \\
Citrulline & $1^{*}$ & $2.33 \pm 0.33(42.4)$ & $1.83 \pm 0.16(33.3)$ & $1.33 \pm 0.61(24.2)$ \\
& 2 & $3.16 \pm 0.54(37.2)$ & $2.66 \pm 0.49(31.3)$ & $2.66 \pm 1.47(31.3)$ \\
Asparagine & $1^{*}$ & $1.33 \pm 0.61(38.1)$ & $0.83 \pm 0.40(23.7)$ & $1.33 \pm 0.21(38.1)$ \\
& 2 & $2.66 \pm 0.76(38.1)$ & $1.66 \pm 0.55(23.7)$ & $2.66 \pm 0.21(38.1)$
\end{tabular}

$Z_{3}=$ zone 3 (center of the container where snail attractant pellets were located); $Z_{2}$ (zone 2 ) and $Z_{1}$ (zone 1 ) = the middle zone between $Z_{0}$ (outer zone) and $Z_{3}$. Numbers in parentheses are the percent of snails successfully locating snail attractant pellets, i.e., snails in $Z_{3}$, compared to the snails that failed to locate them. Statistically significant $(P<0.05)$ when two-way ANOVA was applied between the number of snails present on SAP containing different amino acids $(*)$ at $50 \mathrm{mM}$ concentration. There was no significant variation in the number of snails present in different zones.

of snails attracted by different amino acids at any concentration, except $50 \mathrm{mM}$. This indicates that snail receptors can only differentiate the amino acids when they reach a certain threshold level (50 mM). At higher concentrations, again the differentiation of amino acids by snails is not significant. The gastropods are able to detect their food sources sensing amino acids as indicators of the presence of their food (11-15). Amino acids are released by aquatic plants and some algae. It is possible that the amino acid to which each species is sensitive is related to the detection of the extent of decay in the plant material on which it feeds. Finally, we suggest that the snail L. acuminata, an intermediate host of Fasciola species, might be controlled by using bait formulations containing highly attractive compounds and specific molluscicides. 


\section{References}

1. Singh O \& Agarwal RA (1981). Toxicity of certain pesticides to two economic species of snail in northem India. J ournal of Economic Entomology, 74: 568-571.

2. Agarwal RA \& Singh DK (1988). Harmful gastropods and their control. Acta Hydrochimica et Hydrobiologica, 16: 118-138.

3. Uhazy SL, Tanak RD \& Maclannis AJ (1978). Schistosoma mansoni: identification of chemicals that attract or trap its snail vector Biomphalaria glabrata. Science, 201: 924-926.

4. Croll RP (1983). Gastropod chemoattraction. Biological Reviews, 58: 293-310.

5. Audesirk TE \& Audesirk GJ (1985). Behaviour of gastropod molluscs. In: Dennis Willow AO (Editor), The Mollusca. Vol. 8. Academic Press, London, 1-94.

6. Masterson C \& Fried B (1992). Chemoattraction and dietary preferences of Biomphalaria glabrata (gastropoda: planorbidae) for leaf lettuce, tetramin and hen's egg yolk. Comparative Biochemistry and Physiology, 103: 597-599.

7. Abd El-Hamid AZ (1996). Amino acids as attractant to Biomphalaria alexandrina snails intermediate hosts for Schistosoma mansoni. Egyptian J ournal of Bilharziasis, 18: 13-26.

8. Madsen $H$ (1992). A comparative study on the food locating ability of Heliosoma duryi, Biomphalaria camerunensis and Bulinus truncatus (pulmonata:planorbidae) J ournal of Applied Ecology, 29: 70-78.
9. Sokal RR \& Rohlf FJ (1973). Introduction to Biostatistics. W.H. Freeman and Co., San Francisco, CA, USA, 185-207.

10. MacLannis AJ , Bethal WM \& Comford EM (1974). Identification of chemicals of snail origin that affect Schistosoma mansoni miracidia. Nature, 248: 361-363.

11. Thomas JD (1982). Chemical ecology of the snail hosts of Schistosomiasis: snail-snail interaction and snail-plant interaction. Malacology, 22: 81-91.

12. Sterry PR, Thomas JD \& Patience RL (1985). Changes in the concentrations of short chain carboxylic acids and gases during decomposition of the aquatic macrophytes Lemna paucicostata and Ceratophylum demersum. Freshwater Biology, 15: 139-153.

13. Thomas J D, Kowalczyk C \& Somsundaram B (1989). The biochemical ecology of Biomphalaria glabrata, a snail host of Schistosoma mansoni: short chain carboxylic acid and amino acids as phagostimulant. Comparative Biochemistry and Physiology, 93A: 899911.

14. Kpikpi J EK \& Thomas J D (1992). A study of the sugar chemoreception niches of two bulinid snail hosts of schistosomiasis. Annals of Tropical Medicine and Parasitology, 86: 181-186.

15. Abd-El-Hamid AZ \& Madsen H (1995). Chemoreception of Biomphalaria alexandrina snails to different sugars. International Conference of Schistosomiasis, March 12-16, Cairo, Egypt. 